\section{O Cinema Estrutural e a Ruptura com o Cinema Institucional}

Structural Film and the Break with Institucional Cinema

Frederico Franco Rimoli Universidade do Vale do Rio dos Sinos. Escola da Indústria Criativa.

\section{RESUMO}

O presente trabalho busca, através de uma reflexão empírica, compreender como o cinema estrutural - vertente experimental da sétima arte desenvolve um caráter anticapitalista a partir de suas peculiaridades estéticas. Para dar início a esse estudo, apresentase uma exposição teórica de como se comporta o cinema institucional, que não representa apenas o cinema clássico, mas toda a gama de produções cinematográficas com perfil narrativo. Em seguida, é necessário compreender a gênese do pensamento artístico que questiona o institucional: a teoria das vanguardas, inspirada por movimentos artísticos como futurismo, dadaísmo e begin this study, a theoretical exposition of how institutional cinema works is presented, which not only represents classic cinema, but the entire range of cinematographic productions with a narrative style. Then, it is necessary to understand the genesis of artistic thought that questions the institutional: the avant-garde theory, inspired by artistic movements such as futurism, dadaism and expressionism. Finally, structural cinema is presented from its expressionismo. Por fim, é apresentado

o cinema estrutural a partir de suas manifestações teóricas e práticas, criando um breve entendimento da maneira como o estruturalismo cria sua crítica. As questões referentes são expostas com o objetivo principal de apresentar como um ramo cinematográfico não-narrativo pode configurar um ato de resistência por meio de suas características formais.

PALAVRAS-CHAVE: cinema estrutural; cinema experimental; representação; ilusionismo. theoretical and practical manifestations, creating a brief understanding of the way structuralism creates its criticism.

The related question is exposed with the objective of presenting a non-narrative cinematographic branch that can constitute an act of resistance through its formal characteristics.

KEYWORDS: structural film; experimental film; representation; illusionism. 


\section{INTRODUÇÃO}

Os estudos da filosofia pós-hegeliana, capitaneados por Karl Marx (1818 1883) e Friedrich Engels (1820 - 1895), apontam para uma nova direção a respeito dos estudos historiográficos. $\mathrm{O}$ termo dialética, antes utilizado em prol da arte retórica grega, agora ganha uma nova abordagem, visando compreender fenômenos históricos e, sobretudo, sociais. Como relembra Konder (2008), uma das pedras angulares dos estudos marxistas, a segunda lei da dialética está posicionadajustamentenacompreensão historiográfica dos processos que desembocaram nos paradigmas de um tempo, representando um dos primeiros passos para uma ruptura com a estrutura social vigente.

Marx (2011) em Grundrisse, por exemplo, disseca a sociedade burguesa a fim de compreender como, a partir das minúcias das estruturas sociais, se cria um estado de controle de classes e de dominação do homem pelo homem. Retirando o véu da ideologia das complexidades sociais,

o filósofo alemão passa a construir

os primeiros passos de sua teoria revolucionária. No ramo artístico, mais especificamente no cinema, o caminho não é distinto. Por mais que busque um distanciamento da ideologia, a sétima arte não está imune às implicações sistemáticas do modelo de produção hegemônico. A questão aqui vai muito além de elementos discursivos: está posicionada nas características formais e estéticas do modelo de produção cinematográfico.

No epicentro da arte contemporânea no underground ${ }^{7}$ dos Estados Unidos, surge uma vertente cinematográfica experimental que busca justamente compreender os mecanismos do cinema dominante para, então, subvertê-los. Entre a arte minimalista de Donald Judd (1928 - 1994) e as performances de Marina Abramovic (1946-), desenvolvese o cinema estrutura/ ou, como aponta Sitney (2002, p. 347), "o mais significativo desenvolvimento no cinema de vanguarda norte-americano desde as tendências das formas mitopoéticas no início dos anos 1960". Em uma rápida definição, o cinema estrutural representa uma série de filmes que propõem uma abordagem materialista do filme, focando exclusivamente em suas particularidades físicas e explorando suas dimensões, suas especificidades e seus limites.

A proposição do presente trabalho se dá, sobretudo, por meio de uma revisão geral de conceitos que englobam desde as teorias da representação de Jacques Aumont (1942 -), passando pela construção da ideia de vanguarda de Peter Bürger (1936 - 2017) e François Albera (1948 -), e culminando na teoria do cinema estrutural de Peter Gidal (1946-), buscando compreender de que maneira os filmes estruturais rompem com a lógica burguesa-capitalista do fazer cinematográfico e, dessa forma, configuram um novo horizonte para o cinema. Ou melhor: o cinema estrutural é uma oposição ao cinema normativo?
Como se dá essa construção de possível oposição?

Para um desenvolvimento coeso da pesquisa, é proposta uma divisão clássica, contendo um tópico de retrospectiva teórica - buscando abordar os principais pontos de cada teoria exposta -, um seguinte tópico dedicado à análise a partir dos enunciados estudados anteriormente e, por fim, o fechamento do trabalho apontando as considerações finais atingidas. No âmbito metodológico, há de explicitar um movimento de desconstrução a partir de uma revisão do cinema institucional, apoiado em Andrew (2002), Burch (1977) e Aumont (2012) para, depois, apresentar a oposição proposta pelo cinema estrutural - movimento teórico capaz de criar uma dinâmica dialética de tese e antítese. A síntese, no entanto, é construída de maneira quase intrínseca à secção dedicada ao estrutural, já que os autores abordados são capazes de desenvolver conclusões precisas a respeito da ligação do estruturalismo 
com o antiburguês. A conclusão, dessa forma, atua como um apêndice às proposições do tópico de número três, colocando em perspectiva geral as principais ideias extraídas da cisão entre clássico e estrutural.

\section{DO NORMATIVO À VANGUARDA}

Seguindo os passos da teoria marxista e marxiana, antes de uma análise voltada para o movimento estrutural propriamente dito, retorna-se a um entendimento da institucionalização de um fazer cinematográfico, aqui nomeado como cinema normativo. Posteriormente, é necessário compreender como se dá a gênese dos primeiros pensamentos de real desconstrução e autocrítica das regras normativas da sétima arte: a teoria das vanguardas. Esses primeiros processos servirão de base para um entendimento mais claro das distâncias estéticas entre o modo de representação hegemônico e a origem político-revolucionária das artes vanguardistas.

\subsection{0 modelo de representação mainstream}

Entender os mecanismos de dominação, antes de tudo, é parte chave de qualquer processo de subversão - seja artístico, seja político, como fez Karl Marx. Assim como fez Eisenstein (1898 - 1948), segundo Andrew (2002), estudando o desenvolvimento da montagem clássica para, depois, realizar a desconstrução com a montagem de atrações, iniciase, aqui, uma recapitulação das grandes categorias que marcam o cinema mainstream como um todo. Se há algum processo de ruptura, é necessário, antes de tudo, entender contra o que se dá essa ruptura para, dessa forma, encontrar os melhores meios para tal afronta contra o sistema hegemônico.

A ideia de uma consolidação de um sistema padrão capitalista para a atividade cinematográfica remete, principalmente, à ascensão dos Estados
Unidos da América como uma grande potência econômica do pós-primeira guerra mundial, como nota Burch (1977). Isso não significa, no entanto, que o cinema predecessor às produções estadunidenses partiria de lógicas proletárias, muito pelo contrário; por mais que a classe trabalhadora estivesse representada nas imagens exibidas, havia, sempre, uma exploração desta por parte do diretor oriundo da burguesia industrial do início do século. As lógicas industriais eurocêntricas de França e Suécia, países dominantes no ramo do cinema até 1915, segundo Costa (2006), também eram responsáveis por uma visão burguesa desse vaudeville?

O desenvolvimento de uma lógica industrial do cinema, seguindo a economia mundial como um todo, propiciou à sétima arte um caráter mercadológico, comercial. O entendimento do cinema enquanto objeto comercial é tema central de uma evolução técnica e, também, estética do cinema. Segundo Cubitt (2004) e
Burch (1977), essa evolução comercial do cinema é uma forma de serialização e homogeneização dos modelos cinematográficos; a ideia quase fordista de uma mecanização da indústria do cinema está diretamente ligada à tendência industrial que vem desde o tempo de Karl Marx (2011). Para o autor, a arte dentro de uma sociedade burguesa "cria um público capaz de apreciar a arte e de sentir prazer com a beleza. A produção, por conseguinte, produz não somente um objeto para o sujeito, mas um sujeito para o objeto" (MARX, 2011, p. 66). As bases para instrumentos de dominação estão postas e basta, agora, entender como isso ocorre.

Dentro do cinema hegemônico, a imagem é utilizada a partir de estratégias ilusionistas para extasiar o espectador, deixando-o imerso em um mundo estranhamente similar ao seu. Segundo Aumont (2012), esse efeito não é exclusivo propriamente do cinema, mas, sim, das artes visuais como um todo, que se apropriam de ferramentas ilusórias, 
como a perspectiva tridimensional. O obra fechada. O diretor, como autor cinema, no entanto, possui a ferramenta do tempo; seja o tempo esculpido ou bruto, a arte cinematográfica aproxima o espectador de seu mundo ilusório por meio das convenções temporais. Ainda de acordo com Aumont,

Mais amplamente, pôde-se sustentar que todas as artes representativas, em nossa civilização, foram fundadas em uma ilusão parcial da realidade, dependente das condições tecnológicas e físicas de cada arte. É em particular a tese de Rudolf Arnheim [(1904 - 2007)] [...], em que distingue o cinema das outras artes representativas por produzir uma ilusão de realidade bastante forte, baseada no fato de que o cinema dispõe do tempo e de um equivalente aceitável de volume, a profundidade (AUMONT, 2012, p. 99-100, comentário nosso).

Gidal (1990) postula que outro aspecto da dominação ideológica do cinema burguês é a ideia do filme enquanto máximo da película, não deixa margens para uma construção dialética ao lado do espectador - lacunas narrativas, no entanto, não representam uma espécie de relação dialética descrita pelo autor. Por mais que seja uma afirmação válida, o contraponto de Baudry (1983) é necessário: o veículo, para ele, não possui uma propensão ideológica inerente à sua natureza: por mais que o cinema mainstream tenha, em sua maioria, vocação capitalista, não existe nada que impeça os autores de realizarem subversões a esse sistema. Assim como Schiller (1759 - 1805) utilizava-se de estruturas poéticas normativas para realizar críticas ao sistema vigente, Luís Buñuel (1900 - 1983) o faz no campo do cinema.

A partir dos enunciados de Burch (1977), também há de se introduzir um pensamento acerca da antropomorfia presente no cinema comercial em decorrência da utilização da figura do ser humano. Em sua maioria, a parcela mainstream da sétima arte, além de se calcar em narrativas humanas, expondo tanto suas virtudes quanto seus defeitos, também se apropria da fisicalidade dos atores. Recursos como close up, tão analisados por Béla Balasz (1884 - 1949), são fatores que remetem diretamente às possibilidades de identificação entre audiência e filme. A exaltação da persona como elemento máximo do filme é decorrente das reflexões de Benjamin (2017) relativas à aura da imagem fotográfica. Para o autor alemão, representação humanoide ganha novo significado aurático por remeter ao culto à saudade. Como visto até aqui, a identificação do público com a tela de cinema, criando possibilidades imersivas, é elemento chave do desenvolvimento de um modo de representação padrão. Em geral, há de se compreender, a partir dos tópicos apontados, que os valores do cinema capitalista, comercial, mainstream, estão ligados a uma dominação ideológica por meio de suas características formais - por mais que possam ser utilizadas em prol da subversão. Neles, as narrativas se sobrepõem à forma fílmica através de uma identificação do espectador com o modelo representativo, similar, por exemplo, à visão renascentista do quatroccentono qual a figura humanaéo centro de toda a atenção espectatorial.

\subsection{Vanguardas: a primeira ruptura}

Não existe ao certo uma origem específica do uso do termo avant garde para as artes em geral, mas Albera (2012) constrói uma breve linha temporal sobre os primórdios do vocábulo. Stricto sensu, "vanguarda" é proveniente do vocabulário militar, representando a primeira linha de batalha, composta por soldados que puxam a fila de todo um batalhão. Posteriormente, o termo fora adaptado para o ramo artístico com a finalidade de categorizar os movimentos que, de certa maneira, representavam pioneirismo acerca de determinado meio de expressão. A relação entre essa 
rápida definição com a origem militar do termo é imediata: os dois versam sobre aquilo que vem primeiro.

As quebras representadas pelas artes de vanguarda são vistas, inclusive, a partir de uma ruptura quase total com três grandes pontos da arte na sociedade burguesa. Abordados nos seguintes parágrafos, são: 1) a crítica à própria arte - levemente citado anteriormente; 2) a questão do termo "arte"; e, por fim, 3) a problemática da autoria.

Sasse (1984) formula a ideia de que a grande separação dos movimentos modernos e do vanguardismo se estabelece a partir da autocrítica. Enquanto os primeiros estariam enquadrados na categoria marxiana de crítica imanente ao sistema, a vanguarda vai ao encontro da autocrítica. E como se dá esse caráter autocrítico? Justamente utilizando o entendimento da posição da arte na sociedade burguesa como elemento para a desconstrução da instituição arte. Uma quebra com o idealismo da arte-pela-arte instaurado pela ideologia hegemônica representaria, dessa maneira, uma nova proposição formalista, retirando o foco do conteúdo artístico e lançando-o em direção à desconstrução dos valores da arte burguesa pela forma artística.

Fechado esse primeiro ponto, é importante, nesse momento, focar na instância do próprio termo "arte". Enquanto a arte burguesa é interpretada puramente através de sua similaridade visual e estética com outras obras, o vanguardismo apenas é visto como arte quando o espectador realiza o exercício mental de pensar na própria categoria artística. Uma obra avant garde só é validada como "obra de arte" porque provoca, ataca, a própria arte como um todo. Além disso, a própria questão das instituições de arte, museus, galerias e afins é, segundo Bürger (1993), o principal motivo da categorização. Por fim, o último tópico refere-se à autoria. Se dentro da lógica burguesa "a obra de arte autônoma dá-se individualmente, [...] é concebida como singularidade radical" (BÜRGER, 1993, p. 93), o avant garde busca questionar esse local de unicidade da arte. Com o advento do século $X X$, a produção de imagens aumenta consideravelmente, e debates acerca da serialidade são trazidos para o ramo das artes por meio de expoentes vanguardistas como Marcel Duchamp (1887 - 1968). Buscando questionar a singularidade da arte como um todo, o artista francês, ao desenvolver L.H.O.O.Q(1919) - sátira do clássico La Gioconda (1503) - debocha do caráter de unicidade da arte ao reproduzir a obra de Da Vinci (1452 1519) com as intervenções próprias e o infame xingamento proveniente dos fonemas das letras do título.

Burch (1977) em seu texto sobre o modo hegemônico aponta, também, para um primeiro momento de ruptura com tais regras a partir da figura do construtivismo russo, ou montagem soviética. Segundoo autor, nesse primeiro momento, o grupo de cineastas capitaneados por Sergei Eisenstein e Dziga Vertov (1896 - 1954) apresenta uma primeira experiência a fazer frente com os preceitos clássicos já estabelecidos. A montagem, que dentro do clássico trabalha em prol da ilusão e da fluidez, para os soviéticos, é instrumento de choque e estranhamento, indo além do ilusionismo e deixando a forma fílmica em evidência. Muito mais do que uma transparência, talvez pela primeira vez em grande escala, o veículo do cinema é colocado como protagonista.

A busca por uma revolução, por uma mudança drástica na estrutura social, é um elemento que caminha de mãos dadas com as vanguardas. Tais contextos despertam a consciência social da arte que, ao invés de se manter distante dos problemas sociais, junta-se à luta e questiona seu próprio uso dentro da esfera social. A busca por uma revolução é também dever artístico, que antes de se voltar para uma crítica direta e didática, deve se voltar para sua essência. É esse o caminho capaz de resgatar a semente vanguardista do início do século XX ao final dos anos 1950, quando novas 
tendências artísticas e cinematográficas surgem como alternativa aos moldes hegemônicos tradicionais.

30 CINEMA ESTRUTURAL: UMA NOVA ALTERNATIVA

Em sua clássica definição a respeito do cinema estrutural, Sitney (2002) afirma que esta estética vanguardista é composta por filmes que se concentram em transitar por entre quatro características: a posição fixa de câmera, o flicker, a cópia em loop e a refilmagem da tela. Contudo, sua mais importante reflexão é: o filme estrutural tem sua potência localizada na forma do filme; o conteúdo é vazio, a forma é o cerne da obra. Concluindo: esta vertente cinematográfica nega aquilo que mostra o filme, focando, apenas, nas especificidades do veículo.

As definições e os limites do cinema estrutural não se limitam à escrita de Sitney (2015). A vertente estrutural não é homogênea e não é, muito menos, um movimento no qual todos os filmes dialogam de maneira imediata - justiça seja feita, o autor deixa esses detalhes claros em seu ensaio. Peter Gidal (1990),

por exemplo, aponta o cinema estrutural como uma corrente de pensamento que se expande para além dos cinemas de vanguarda, chegando a atingir Godard (1930 -) e Straub (1933 -) e Huillet (1936 - 2006). Chega-se até mesmo a propor uma nomenclatura diferente daquela aplicada por Sitney (2015): cinema materialista. Vale lembrar que Gidal (1990) trata o cinema estrutural a partir de uma ótica para além do cinema experimental propriamente dito. Mesmo assim, como ele mesmo aponta (1978), o cerne das teorias apresentadas em seus textos estão presentes naquilo que Sitney (2015) batiza de cinema estrutural - filmes que se utilizam da teoria do cinema materialista de maneira mais radical.

A partir de um olhar sobre o cinema estrutural como um todo, Gidal (1990) nota que um dos principais preceitos dessa vertente vanguardista é, justamente, desconstruir a ideia de uma representação ilusória do mundo natural. Se a natureza da imagem é, inevitavelmente, representacional, não há de se negar sua principal característica: a questão é justamente mostrar os movimentos ilusórios do veículo. O autor desenvolve que, no cinema estrutural, os filmes buscam mostrar ao espectador que nada daquilo que surge na tela é, de maneira alguma, natural: o filme é, necessariamente, uma reprodução física e finita do mundo material. Dentro do estruturalismo, "os incidentes visuais (o "conteúdo") dessas obras são "mínimos", pouco diversos (...) subordinados a estruturas formais" (DUARTE, 2017, p. 13) - como principal exemplo, vê-se Wavelength (1967), no qual as pequenas ações presentes na obra pouco importam, o grande foco do filme reside no movimento do zoom. Outra característica dos filmes estruturais é a exploração exaustiva de alguma particularidade do cinema, seja a alternância de frames ou até mesmo movimentos de câmera.

Nessa vertente de vanguarda em específico, ocorre uma anulação, ou supressão, de estruturas narrativas, para deixar em primeiro plano analítico as questões materiais do filme. 0 cinema estrutural volta suas atenções efetivamente para tornar a forma fílmica o principal conteúdo. A ideia de questionar, além da ideologia, a estética do cinema mainstream, corrobora esse movimento; o conteúdo, as reflexões, vão além daquilo que é mostrado e buscam questionar as maneiras e os processos que culminaram naquele resultado em específico. Em The flickr (1965), o entendimento narrativo é nulo, já que a incansável e ininterrupta justaposição de frames pretos e brancos direciona os olhares do espectador para o mecanismo básico do cinema. Dito isso, há uma retórica conceitual no exemplo citado, ultrapassando a própria imagem e atingindo a instituição "cinema" ("arte") como um todo. 
Para Gidal (1990), a desconstrução das estruturas clássicas de narrativa e de forma são resultado direto da herança vanguardista dos anos 1920. O ato de desconstruir é utilizado por inúmeros cineastas, como Pasolini (1922 - 1975), Bergman (1918 - 2007) e até mesmo Antonioni(1912-2007), quedestrincham narrativas clássicas, mas ainda se veem presos na semiótica usual do cinema hegemônico. O cinema estrutural, no entanto, vai além da desconstrução e se encontra na subversão: desconstrói o próprio mecanismo cinematográfico, desnudando-o e deixando-o aparente para o espectador. A negação dos símbolos dominantes e a proposta de uma nova história para o cinema, que se distancie de modelos já social e comercialmente aceitos, é um ato que visa ressignificar a arte cinematográfica, e não apenas um de seus aspectos formais.

A noção de "acaso" para Noel Burch (1992) está intrinsecamente ligada a todo conteúdo exposto até o momento.
Para o autor, as obras de vanguardas se distanciam do cinema comercial ao negarem a ideia de uma obra sagrada, fechada, na qual o gênio do diretor impõe sua visão de maneira calculada - ao melhor estilo de ferro de Hitchcock (1899 - 1980). A obra aberta, construída através do acaso da existência mundana, é um universo não-natural em que ocorre um "sentimento de que existe um mundo realmente incontrolável além dos limites da tela [ou seja, dos limites do mundo projetado]" (BURCH, 1992, p. 145, comentário nosso). Imaginar um universo para além da representação cinematográfica é a exata antítese do ilusionismo clássico. Assim como a tradição vanguardista, o cinema estrutural é composto por obras lacunares que apenas com a participação externa do espectador atingem sua totalidade.

As relações dialéticas entre filme e público permeiam as vanguardas desde os anos 1920 e culminam nos anos 1960 e, sobretudo por causa da efervescência teórica e artística do tempo, transformam o espectador em um elemento ativo do discurso cinematográfico, uma espécie de interlocutor, segundo Burch (1992). As aberturas para margens interpretativas e reflexivas acerca do mecanismo cinematográfico são, segundo Gidal (1978), uma afronta à tentativa de dominação capitalista - que se mantém viva através da ideia de uma falsa autonomia das massas perante o filme. Para o autor, nem mesmo ambiguidades narrativas e de personagens são capazes de fugir da lógica sistemática da imposição ideológica do mercado cinematográfico capitalista. Nas palavras do autor,

[no cinema estrutural], cada filme não é apenas estrutural, mas também estruturante [...]. O espectador está formando um 'filme' igual e possivelmente mais ou menos oposto em sua cabeça, constantemente antecipando, corrigindo, recorrigindo - constantemente intervindo na arena de confronto com a realidade dada (GIDAL, 1978, p. 3).

Gidal (1990) propõe que a ruptura total com a dominação ideológica do capitalismo no cinema só é concebível por meio da construção de espectador engajado e ativo, que não se deixe acomodar pelos aparatos ilusórios do cinema hegemônico. Tornando a audiência ativa e construtiva, o filme passa a ser construído, também, pelo espectador. Há, aqui, uma via de duas mãos: ao mesmo tempo em que o público deve se abrir de maneira crítica à obra, os artistas devem cumprir seu dever vanguardista de voltar suas atenções para a instituição "cinema". Segundo Andrew (2002), tudo issoé, para Eisenstein, mera utopia se não aliado à revolução socialista, a representação sócio-política da libertação popular das amarras capitalistas.

Mudarosrumosea história docinema não é possível sem um novo entendimento da questão do movimento (ou da ilusão deste) dentro da sétima arte. Como visto 
anteriormente, uma das estratégias ilusionistas utilizadas é uma reprodução fidedigna do movimento humano ou natural. Contudo, o mecanismo cinematográfico é incapaz de apresentar uma relação realista com o movimento. Nas palavras de Peter Kubelka (1934 -), entrevistado por Mekas (1970, p. 290, tradução nossa): “O cinema não se trata de movimento. [...] O cinema não é movimento, mas, sim, a projeção de imagens fixas em um ritmo acelerado". Ernie Gehr (1941 -), em Serene velocity (1970), retorna à Man Ray (1890 - 1976) e, a partir de imagens stills, revela a ilusão de movimento capaz de ser criada pelo cinema. O próprio título, uma clara ironia à utopia do movimento cinematográfico, é um compilado de uma mesma imagem sendo repetida, mas com leves variações de enquadramento, que cria uma falsa aproximação da câmera com o fundo da imagem.Como a citação de Mekas (1970), a rapidez dos frames, com intervalos mínimos, ou quase inexistentes, entre si, são fatores, comprovados por Gehr, que criam a suposta reprodução ideal do movimento da realidade material.

Os propósitos anti-ilusionistas estão baseados, para Gidal (1990), no conceito de arbitrariedade. Esse termo, oriundo da política, representa uma ideia de que nada pode ser visto como natural, visando expor a importância da ideologia e da autonomia do pensamento humano na vida social. Se, por um lado, o cinema hegemônico busca a naturalização ilusória do cinema, por outro lado, o estruturalismo se apoia na arbitrariedade em busca do "conceito de significante vazio, da tentativa de [...] construção de tal significante em direção à não identidade" (GIDAL, 1990, p. 12), no qual o espectador percebe que o processo de observar o filme é, sobretudo, ver uma representação material das particularidades físicas do cinema.

Ao mecanizar o cinema, utilizando o próprio veículo como instrumento teórico, é inevitável relacionar a prática do cinema estrutural com experiências metalinguísticas. Gidal (1978) diz que o caráter reflexivo do filme não está relacionado à sua potência filosófica, metafórica ou alegórica; a reflexão proposta pelo cinema estrutural está baseada na revisão do próprio veículo do cinema e de suas particularidades:

O filme opera dialeticamente, na medida em que foi alcançada uma estrutura prévia que indica as operações a serem executadas pela câmara e pelo operador de câmera, e isso, durante o decorrer do filme, interage com as variáveis da situação da filmagem (GIDAL, 1990, p. 33).

Observar o cinema como o resultado da união das máquinas e da força humana é, possivelmente, um retorno ao pensamento construtivista da arte baseada no entendimento do meio de expressão como o produto da labuta artística.

LeGrice (1978), por exemplo, recupera uma específica obra da montagem soviética como inspiração da questão metalinguística no cinema estrutural. Para ele, Um homem com uma câmera (1929), de Dziga Vertov, foi um marco que inaugurou um processo de deixar visíveis as manipulações da câmera para o espectador, buscando uma filosofia acerca do próprio cinema. A revelação da câmera e, quiçá, do próprio diretor do filme, aliada ao modelo de representação estrutural, tem como finalidade um foco exclusivo na forma fílmica, quase anulando qualquer tentativa de conexão narrativa. Para o autor,

O filme é complexo apesar da simplicidade do cenário, que só é apreendido lentamente. Particularmente, sucinto é o modo como o efeito de manipulação da câmera, como a mudança de foco, é visto na imagem simultaneamente com uma visão de como ele é realizado. Não há outro 'conteúdo' senão o funcionamento da própria câmera, considerada suficiente e até poética (LEGRICE, 1978, p. 24, tradução nossa). 
Se Benjamin (2017) aponta que a figura humana éa relação mais próxima possível de uma aura da imagem fotográfica, o teórico postula, também, que o cinema é responsável pela destruição do conceito de aura através da figura humana. O cinema estrutural, por outro lado, lida de maneira particular com a questão da figura humana ou, como será tratado aqui, da antropomorfia do próprio filme. Aqui, há uma relação dialética entre as relações humanas para com a máquina. Se por um lado, como vê LeGrice (1978), os filmes estruturais representam uma ultramecanização do filme, entendendoos como um instrumento puramente mecânico (reiterado pela ideia da arbitrariedade), por outro lado, o fato de se negar a assumir a representação ilusória do cinema hegemônico concede à sua corrente a ideia de uma intervenção humana perante a realidade material. É razoável concluir que a representação não ilusória é capaz de ratificar ambas as ideias expostas, criando uma coexistência dialética da intervenção humana no cinema estrutural. Nas palavras de LeGrice (1978, p. 23, tradução nossa), uma "dialética complexa entre resposta existencial subjetiva, de um lado, e um conceito estrutural reflexivo, de outro". Busca-se, nesse trecho, exemplificar o uso da figura humana a partir da obra de Hollis Frampton (1936 - 1984), (nostalgia) (1971). Aqui, não há relação aurática entre espectador e a imagem: a figura humana é subjugada, posta como fator secundário da obra. Contudo, é, da mesma forma, a ação humana através da figura mecânica da câmera cinematográfica e do próprio fogão que expõe o veículo cinematográfico, desnudando-o para o espectador. A imagem queimada, dando a ideia da finitude da imagem, é, novamente, fator que mostra a volatilidade da ação do ser humano através da representação do mundo natural.

Além disso, é importante ressaltar, mais uma vez, a influência direta da teoria das vanguardas no processo do cinema estrutural. Ao se voltar contra às peculiaridades formais do cinema mainstream e não apenas às convenções narrativas e aos desvios estéticos básicos, o cinema estrutural é capaz de estabelecer uma importante autocrítica do uso da própria imagem. Ao aceitar sua natureza de veículo de representação bidimensional e negar aparatos ilusionistas, ocorre uma clara reflexão acerca do próprio material fílmico - desde sua base e os frames até as questões temporais e de movimento. Enquanto o modelo hegemônico propõe uma espécie de alienação das massas e uma identificação massiva por parte do público, os estruturalistas fazem o contrário: distanciam o espectador dos recursos ilusórios a fim de criar um pensamento crítico do próprio veículo cinematográfico.

\section{CONSIDERAÇÕES FINAIS}

Arte e política são dois elementos que não se separam. Por mais que nem sempre a política esteja evidente na obra de arte, como em A chinesa (1967), de Jean-Luc Godard, ou Guernica (1937

-), de Pablo Picasso (1881 - 1973), os contextos sociais e políticos dizem muito sobre como uma obra se encaixa dentro da política de seu tempo. Ginzburg (2014), ao desenvolver uma leitura a respeito do quadro $A$ morte de Marat (1793), de Jacques-Louis David (1748 1825), aponta como o entorno político da Revolução Francesa está presente dentro da pintura. Por mais que não existam diretas referências ao contexto político da época, David consegue, a partir de recursos de enquadramento e deênfase em pequenos detalhes (comoo calendário, elemento de apreço do autor ao longo da análise), apontar a influência social em sua obra. A política vai muito além da figura de Marat, personagem importante do processo revolucionário e pós-revolucionário na França do século XVIII: sua estética também se inspira na revolução.

A mensagem transmitida por Ginzburg (2014) vai ao encontro do propósito 
deste escrito. O cinema estrutural, como já dito, é o cinema da forma como conteúdo. Nele, não existem pretensões narrativas, ou seja, não existem propostas temáticas que sejam capazes de desencadear uma mensagem de crítica social. No entanto, a maneira com a qual os diretores lidam com a forma do filme é a chave da questão. Se o cinema hegemônico, segundo Gidal (1990), representa um reflexo fidedigno da sociedade burguesa-capitalista do século XX, a ruptura estrutural desses moldes institucionais é, também, uma afronta ao sistema: um ato político. Por mais que os próprios autores não assumam tal caráter, seu modo de lidar com o material do filme é, sem dúvida, uma proposta de intervenção revolucionária.

A própria ligação com os preceitos vanguardistas de Bürger (1993) dá a tônica de uma influência política nas obras estruturais. O cinema estrutural e a política estão conectados por algo que se situa muito além da estética. A gênese do pensamento vanguardista os mantém unidos por um cordão umbilical cuja força apenas cresce ao longo dos tempos. Se Snow (1928 -), Frampton, Wieland (1930 - 1998) e Conrad (1940 - 2016) deixam propositais lacunas em suas obras, sejamos nós a preenchêlas para, dessa forma, fazer aquilo que Debord (2003) suscita em seu livro $A$ sociedade do espetáculo. desvelar o espetáculo e compreender como ele manifesta sua ideologia na sociedade. Se uma vanguarda é uma maneira de revolução, estudá-la também o é? A resposta para essa pergunta, referente a esse trabalho em específico, está mais relacionada à experiência pessoal do que à práxis política. Estudar vanguardas é, definitivamente, uma revolução, mas uma revoluçãointerna;novaspercepções e novos meios de compreender o espetáculo são descobertos, trazendo à vida o espírito rebelde que, desde Duchamp, está plantado no mundo das artes.

\section{NOTAS}

1 Termo inglês que, em tradução livre, significa "subterrâneo". No contexto artístico, refere-se aos produtos culturais que fogem de padrões estéticos e comerciais.

${ }^{2}$ Gênero de entretenimento popular de variedades conceituado entre a segunda metade do século XIX até meados de 1930. 


\section{REFERÊNCIAS}

A CHINESA. Direção Jean-Luc Godard. Intérprete: Anne Wiazemsky, Jean-Pierre Léaud,JulietBerto,MichelSemeniako, Lex de Brujin, Omar Diop, Blandine Jeanson, Francis Jeanson et al. Roteiro: JeanLuc Godard. [S. 1]: Anouchka Films, Les Productions de la Guéville, Athos Films, Parc Films, 1967. (99 min), son., color., 35 mm. Disponível em: https://www. youtube.com/watch?v=uz0Y6jNaCp0. Acesso em: 4 jan. 2021.

ALBERA, François. Modernidade e Vanguarda no Cinema. Rio de Janeiro: Beco do Azougue Editorial Ltda, 2012. ANDREW, J. Dudley. As principais teorias do cinema. Rio de Janeiro: Zahar, 2002. AUMONT, Jacques. A Imagem. Campinas: Papirus, 2012.

BAUDRY, Jean-Louis. Cinema: efeitos ideológicos produzidos pelo aparelho de base. In: XAVIER, Ismail (org.). A experiência do cinema: antologia. Rio de Janeiro: Edições Graal: Embrafilme, 1983.
BENJAMIN, Walter. A obra de arte na era de sua reprodutibilidade técnica. Porto

Alegre: L\&PM, 2017.

BURCH, Noel. Film's institutional mode of representation and the Soviet response.

October, Berkeley, p. 77-96, 1977.

. A práxis do cinema. São Paulo:

Perspectiva, 1992.

BÜRGER, Peter. Teoria da Vanguarda. Lisboa: Vega LTDA, 1993.

COSTA, Flávia Cesarino. Primeiro Cinema. In: MASCARELLO, Fernando (org.). História do Cinema Mundial. Campinas: Papirus, 2006.

CUBITT, Sean. The Cinema Effect. Cambridge: MIT Press, 2004.

DAVID, Jacques-Louis. 1793. A morte de Marat. Óleo sobre tela, 165 x $128 \mathrm{~cm}$.

DAVINCI, Leonardo. 1503. La Gioconda. Óleo sobre tela, $77 \times 53 \mathrm{~cm}$.

DEBORD, Guy. A sociedade do espetáculo. E-Books Brasil, 2003. E-book. DUARTE, Theo Costa. 0 cinema de vanguarda em diálogo com as artes visuais: contrastes e paralelos em experiências brasileiras e norte- americanas (1967-1971). 2017. Tese (Doutorado em Meios e Processos Audiovisuais) - Programa de PósGraduação em Meios e Processos Audiovisuais, Universidade de São Paulo (USP), São Paulo, 2017.

DUCHAMP, Marcel. L.H.O.0.Q. 1919. Lápis sobre tela, $61,5 \times 49,5 \mathrm{~cm}$.

GIDAL, Peter. Theory and Definition of Structuralist/Materialist Film. In:

Structural film anthology. Londres: British Film Institute, 1978.

Materialist film. Londres: Routledge, 1990.

GINZBURG, Carol. Medo, reverência e terror: quatro ensaios de iconografia política. São Paulo: Companhia das Letras, 2014.

KONDER, Leandro. 0 que é dialética. São Paulo: Brasiliense, 2008.

LEGRICE, Malcolm. Abstract film and beyond. In: GIDAL, Peter. Structural film anthology. Londres: British Film Institute, 1978.

MARX, Karl. Grundrisse. São Paulo: Boitempo, 2011.
MEKAS, Jonas. Interview with Peter Kubelka. In: SITNEY, P. Adams (org.). Film

Culture Reader. Nova lorque: Praeger, 1970.

NOSTALGIA. Direção: Hollis Frampton. EUA: 1971. P\&B.

PICASSO, Pablo. Guernica. 1937. Óleo sobre tela, $349 \times 776 \mathrm{~cm}$.

SASSE, Jochen Schulte. Theory of Modernism versus Theory of the AvantGarde. In: BÜRGER, Peter. Theory of the Avant-Garde. Minneapolis: University of Minnesota Press, 1984.

SERENE VELOCITY. Direção de Ernie Gehr. EUA: 1970. Color.

SITNEY, P. Adams. Visionary Film: The American Avant-Garde (1943-2000). Nova lorque: Oxford University Press, 2002.

O cinema estrutural. In: MOURÃO, Patrícia; DUARTE, Theo. Cinema Estrutural. Rio de Janeiro: Caixa Econômica Federal, 2015.

THE FLICKER. Direção de Tony Conrad. EUA: 1965. P\&B. (30 min). Disponível em: https://www.youtube.com/ 
watch?v=rVxNGUTsdJY. Acesso em: 6 jan. 2021.

UM HOMEM COM UMA CÂMERA. Direção de Dziga Vertov. URSS: 1929. P\&B. (68 min).

Disponível em: https://www.youtube.com/watch?v=cGYZ5847Fil. Acesso em: 4 jan.

2021.

WAVELENGTH. Direção de Michael Snow. EUA: 1967. Color. (43 min). 